\title{
Can the human eye detect an offside position during a football match?
}

\author{
Francisco Belda Maruenda
}

One of the most controversial rules in football is the offside rule. A possible explanation is that the human eye and brain are incapable of processing all the necessary visual information to apply the rule

Centro de Salud de Alquerías, $\mathrm{C} / \mathrm{R}$ Fernández Miñarro, No 1, Alquerías, 30580, Murcia, Spain

Francisco Belda Maruenda specialist in family specialist in family practice)

fbeldam@meditex.es
Football is regulated by rules. One referee and two assistant referees direct every game. When the rules are not applied correctly, the final result may be affected. This is often blamed on human error, but is this always true? In this review I analyse the physiology of the human eye to clarify if it is able to process all the information required to apply effectively one of these rules, the offside position.

\section{Eye physiology}

The eyes move to focus on objects and maintain them within their visual field. In doing so, they perform saccadic movements, smooth pursuit movements, vergence movements, vestibular movements, and accommodation.

\section{Saccadic movements}

Saccadic movements are rapid, brief, conjugate movements (that is, the eyes move as a pair). ${ }^{1}$ They occur when the eyes are inspecting an object, when the gaze shifts from one object to another, and during reading. They are necessary for locating objects rapidly in the fovea or for changing the depth of focus of the eye from one object to another within the visual field. This type of movement can be intentional or unintentional. ${ }^{2}$ Unintentional movements are prompted by an object entering the visual field or by the detection of movement.

The latency from onset of the stimulus to onset of the saccadic eye movement is $200 \mathrm{~ms}$, but this depends on the distance of the object, and a shorter interval may be possible. ${ }^{3}$ When the range of movement is greater than $10^{\circ}$ the response time may increase. Other factors-type of stimulus, feature of stimulus, and observer's attention and age-may also affect the latency of saccadic movement. ${ }^{4}$ The speed of movement between objects varies from $10 \mathrm{~ms}$ to $80 \mathrm{~ms}$ and is affected by the angle between the objects. ${ }^{5}$ It is slower with tiredness and lack of attention ${ }^{6}$ and varies with the circadian rhythm.?

\section{Smooth pursuit movements}

These are necessary for following or tracking a moving object smoothly. ${ }^{8}$ The latency period is $125-150 \mathrm{~ms}$, and the speed is influenced by the circadian rhythm and tiredness. ${ }^{7}$

\section{Vergence movements}

Convergence occurs when the gaze shifts from a far to a near object or when it tries to focus on an approaching object. ${ }^{1}$ Divergence is the opposite-transferring the gaze from an intermediate distance to a far or receding object, and more usually gazing into infinity (daydreaming). Latency is $160 \mathrm{~ms}$.

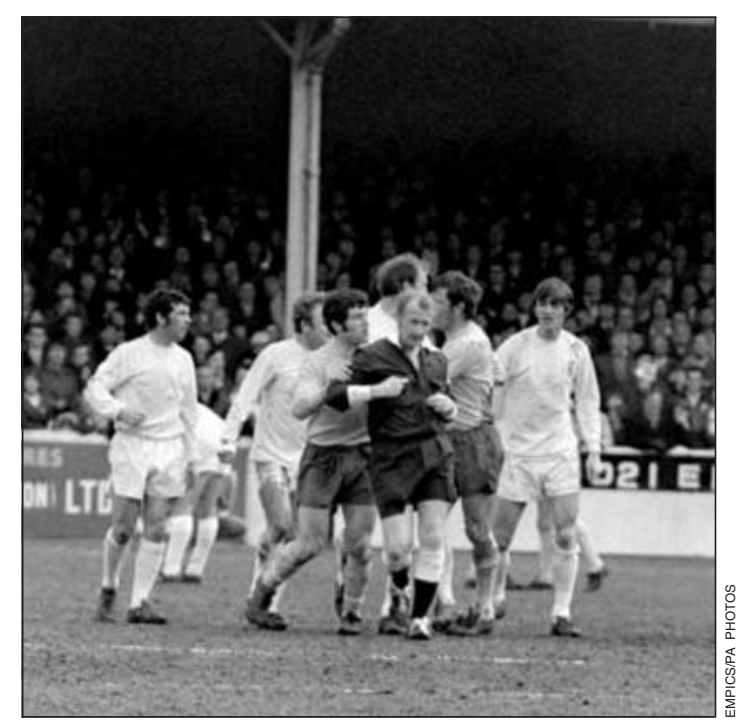

Ruling offside has long been one of the most controversial decisions a referee has to make

\section{Vestibular movements}

These are necessary for maintaining visual fixation when the head moves. The latency time is about $100 \mathrm{~ms}$, and the movements often involve rotatory trajectories.

\section{Accommodation}

To keep objects in focus on the retina, the eye changes the convexity of the lens. ${ }^{9}$ This process has a latency of about $360 \mathrm{~ms}$. The time required to change fixation from far to close vision is about $640 \mathrm{~ms}$, while changing from close to far takes $560 \mathrm{~ms}^{9}$

\section{The offside law}

The law was introduced in 1866 and was written in the current version in $1925 .^{10}$ It clarifies the regular position of the players during the game. To be in an offside position, a player must not only be between the opponents' goal line and the last two players from the defending team, but must be actively involved with the game play at the moment when he or she is passed the ball (fig 1).

\section{Is the human eye able to detect an offside offence?}

To detect an offside position, the human eye must be capable of detecting at least five moving objects at the same time and determining their positions relative to each other. If these objects are not all in the visual field, an offside cannot be judged, and so the referee and the 




Fig 1 The offside position

assistant referees will have to move their heads, thus initiating saccadic movements of the eyes, to locate the objects. The time that the eye needs to detect all the objects is the sum of the eye movements and the accommodation that it has to do.

The ideal condition would be when all the players and the ball are within the visual field. The fixation point would be the ball, and to focus on the relevant players the eye would need for perform saccadic movements. The latency would be $130 \mathrm{ms.}^{3}$ It would then take $140 \mathrm{~ms}$ to focus on the second player, $150 \mathrm{~ms}$ for the third player, and $160 \mathrm{~ms}$ for the fourth. If all the players are within the visual field of the referee or his assistants and there is no need for accommodation, the minimum time needed to detect the three players relevant to an offside position is $160 \mathrm{~ms}$, because of the capacity of the central nervous system for parallel processing of different objects moving at the same time and the visual capacity to store and integrate.


Fig 2 Top: No offside, players in correct position. Bottom: $100 \mathrm{~ms}$ later (players' velocity $7.14 \mathrm{~m} / \mathrm{s}$ ), offside

\section{Offside position: what does the law say?}

A player is in an offside position if he is nearer to his opponents' goal line than both the ball and the second last opponent. A player is not in an offside position if he is in his own half of the field of play or he is level with the second last opponent or level with the last two opponents.

It is not an offence in itself to be in an offside position. A player in an offside position is penalised only if, in the precise moment when the ball touches or is played by one of his team, he is, in the opinion of the referee, involved in active play by interfering with play,

interfering with an opponent, or gaining an advantage by being in that position. There is no offside offence if a player receives the ball directly from a goal kick, a throw in, or a corner kick.

A decision of the International Football Association Board points out that the offside should not be judged when the player receives the ball but when the ball was sent by another team member. A player who is not offside when his team mate sends him the ball or sends a free kick is not penalised for an offside if he runs ahead while the ball is in flight.

By this time all the players would have moved and changed their position. If one of the players is more than 6 metres away from the referee and another is closer than 6 metres, a further accommodation is required. This will take more time and increase the error: latency of the accommodation is $360 \mathrm{~ms}$, and the time required to change fixation from far to close vision is $640 \mathrm{~ms}$ (whereas changing from close to far takes $560 \mathrm{~ms})^{9}$

As more than four players are usually involved in a football action, focusing on all of them requires more time, thus increasing the chance of error. Clearly the change in position is more important when the defending and attacking players are in a borderline position - that is, almost on the same line-and even a small difference in position is relevant.

Football is a dynamic sport where players move fast and across the full area of the pitch. If we assume that an average player runs at a speed of $7.14 \mathrm{~m} / \mathrm{s}$ (equivalent to running 100 metres in 14 seconds), in $100 \mathrm{~ms}$ he will move by $71 \mathrm{~cm}$. If he moves in a direction opposite to the defensive player, the relative change in position between the two will be even greater (fig 2).

\section{Discussion}

Competition in most leagues is fierce, and when referees make errors of judgment the consequences can be far reaching. Many rules in soccer are straightforward and are almost always applied correctly, but others are more prone to misjudgment. One of the most controversial rules to apply is that of offside. ${ }^{11}$ An offside position by one of the attacking players is penalised with an indirect free kick to the defending team, which ends the attackers' attempt to score a goal. Thus, when an offside is wrongly given or when an offside is not detected, a team may be wrongly deprived of or allowed a goal.

Sometimes, it is evident that a referee has misjudged the position of players and unduly penalised one of the teams, but why does this happen? To apply the offside rule correctly, the referee should 


\section{Summary points}

To apply the offside rule correctly in a football game, the referee must be able to keep in his visual field at least five objects at the same time- two players of the attacking team, the last two players of the defending team, and the ball

This is beyond the capacity of the human eye, which may explain why so many offside decisions are controversial

The use of modern technology such as freeze frame television to aid referees' decisions is necessary for the offside rule to be applied correctly

be able to keep in his visual field at least five objects at the same time (two players of the attacking team, the last two players of the defending team, and the ball), and this may not be compatible with the normal eye function-especially as these five objects can be anywhere within the defenders' half of the pitch, an area of at least $3200 \mathrm{~m}^{2}$. This may explain at least some of the instances when television replays of a game clearly show that the offside rule was not properly implemented. The key factor in applying this rule correctly is that the player in question must be in the offside position at the exact time when the ball is passed from a team mate, not when the player receives the ball or when the ball is en route between the players.
By reviewing the physiology of the eye movements likely to be involved in assessing an offside position, I have shown that the relative position of four players and the ball cannot be assessed simultaneously by a referee, and unavoidable errors will be made in the attempt. The use of modern technology during games-freeze frame television and frame by frame analysis-is advisable to limit these errors.

I thank Nuria Navarro Zaragoza for her translation of the paper into English and Joaquín Zaragoza Celdrán for producing the figures.

Funding: None.

Competing interests: None declared.

Burde RM. Control de los movimientos de los ojos. In: Moses R, ed. Fisi ología del ojo de Adler. 8th ed. Buenos Aires: Panamericana, 1988:122-54

Maños Pujol M. Fisiología del sistema sacádico. In: Gavilán C, Gavilán eds. Fisiología y fisiopatología del sistema óculomotor. Madrid: Garsi, 1987:4353.

Gavilán J, Gavilán C, Sarriá MJ. Saccadic movements: a computerized study of their velocity and latency. Acta Otolaryngol 1983;96:429-36.

4 Leigh RJ, Zee DS. The saccadic system. In: Leigh RJ, Zee DS, eds. The neu rology of the eye movements. Philadelphia: FA Davis, 1983:39-68.
.

5 rology of the eye movements. Philadelphia: FA Davis, 1983:39-68. Shickman GM. Funciones visuales que dependen del tiempo. In: Moses
R, ed. Fisiología del ojo de Adler. 8th ed. Buenos Aires: Panamericana, 1988:591-633.

6 Schmidt D, Abel LA, Dell'Osso LF, Daroff RB. Saccadic velocity characteristics. Intrinsic variability and fatigue. Aviat Space Environ Med 1979;50:393.

7 Schalén L, Pyykkö I, Juhola M, Magnusson M, Jänti V, Henriksson N. Intraindividual variation in oculomotor performance in man. Acta Otolaryngol 1984;406(suppl):212-7.

8 Gavilán C, Gavilán J. Fisiología y fisiopatología del sistema óculomotor. Madrid: Garsi,1987:56-66.

9 Moses RA. Acomodación. In: Fisiología del ojo de Adler. 8th ed. Buenos Moses RA. Acomodacion. In: Fisiol

10 Olivós Arroyo R. Teoría del fútbol. Seville: Wanceulen, 1992.

11 International Football Association Board. Laws of the game. Zurich: Fédération Internationale de Football Association (FIFA), 2003:24

\section{An unusual complication of Kocher's manoeuvre}

A Pimpalnerkar, A Datta, D Longhino, N Mohtadi

Royal Centre for Defence Medicine, Birmingham B29 6JD

A Pimpalnerkar consultant in orthopaedics and sports

A Datta

specialist registrar in orthopaedics

Sports Medicine Centre, Calgary, Canada T2N 1N4 D Longhino orthopaedic resident N Mohtadi consultant sports surgeon

BMJ 2004;329:1472-3
A 25 year old man presented to the emergency room with a right anterior glenohumeral dislocation after a fall. He was attended to by a 30 year old, left hand dominant orthopaedic resident. Kocher's manoeuvre was attempted to reduce the dislocation.

As the patient's arm was slowly externally rotated the patient resisted forcefully and suddenly internally rotated his arm. The resident immediately heard a "pop" in his own left shoulder, followed by a burning sensation with subsequent weakness.

The resident was an active individual, who did regular weight training and played competitive ice hockey. He had no previous shoulder problems and denied using anabolic steroids.

On examination there was a loss of the normal anterior axillary fold, bruising in the upper arm (figure), and weakness in adduction and internal rotation. Neurovascular examination was normal. Plain radiographs were unremarkable. Magnetic resonance imaging confirmed a near total rupture of the pectoralis major tendon from its humeral attachment. The marrow signal was normal.

The resident had surgical repair of the tendon five days after the injury. The tendon was reattached to the lateral lip of the bicipital groove using Mitek anchors and number 2 Ethibond. At final follow up at 24 months, the functional range of shoulder movement had returned with good muscle strength and endurance as assessed with isokinetic and functional testing.

\section{Discussion}

Pectoralis major tendon injury, though rare, was first described in 1822 by Patissier. ${ }^{1}$ Such injuries are becoming more common owing to an increasing number of recreational and professional athletes. The mechanism is of a violent eccentric contraction and is associated with doing bench presses, wrestling, and water skiing. ${ }^{2}$

The pectoralis major muscle is a powerful adductor, internal rotator and flexor of the shoulder. The sternocostal and clavicular heads insert at the lateral lip of the bicipital groove to form two separate laminae that are oriented perpendicular to each other. When the arm is abducted and externally rotated the sternocostal fibres are maximally stretched.

Numerous reduction techniques for anterior glenohumeral dislocations have been described. They 